\title{
CONDIÇÕES DE ARMAZENAGEM E QUALIDADE DA MATÉRIA PRIMA: ESTUDO DE CASO EM UMA DERIVADORA DE ALIMENTOS A BASE DE MILHO
}

1 UNISEP - FEFB, Francisco Beltrão - PR, Brasil.

S. P. Dias ${ }^{1}$; J. Rauta ${ }^{2 *}$; C. A. Winck ${ }^{3}$

2 UFRGS - CEPAN, Porto Alegre - RS, Brasil.

3 Universidade do Oeste de Santa Catarina, Chapecó - SC, Brasil.

*jamirrauta27@gmail.com

\section{RESUMO}

O processo de armazenagem, de alguma forma, tem influência direta na produção e no status do produto final derivado. Foi possível constatar neste estudo de caso, que o sistema de armazenagem da empresa está deficitário, necessitando de melhorias, principalmente quando da entrada da matéria prima para produção. Tais problemas, como impurezas, grãos quebrados e ardidos, são gerados no próprio armazém, por falta de prudência e coordenação. Constatações que contrariam o objetivo do armazenamento que é a conservação das particularidades dos grãos e que podem desmerecer os atributos do produto fim, em termos de sabor, características físico químicas e condições visuais. Entre as possíveis causas dos distúrbios, estão a falta de manutenção das máquinas, ineficiência na aeração e aferição da termometria. Como sugestão, além das melhorias sobre os problemas citados, a implantação de gestão e estratégia de estoques, de programas e controle de qualidade, desenvolvimento dos agentes produtores, planejamento e métodos de solução de problemas. O declínio da qualidade da matéria prima, o milho, pode resultar em efeito cadeia, prejudicando o produto final, logo, lesando os resultados financeiros da organização.

PALAVRAS-CHAVE: Milho, Armazenagem, Qualidade, Produção, Controle.

\section{CONDITIONS OF STORAGE AND QUALITY OF RAW MATERIAL: CASE STUDY IN A CORN-BASED FOOD DERIVATIVE}

\begin{abstract}
The storage process, in some way, has a direct influence on the production and status of the derived final product. It was possible to verify in this case study that the storage system of the company is deficient, needing improvements, especially when entering the raw material for production. Such problems, such as impurities, broken and burned grains, are generated in the warehouse itself, due to lack of prudence and coordination. Findings that contradict the objective of storage that is the conservation of the particularities of the grains and that may detract from the attributes of the end product in terms of taste, physical and chemical
\end{abstract}

characteristics and visual conditions. Among the possible causes of the disturbances are the lack of maintenance of the machines, inefficient aeration and thermometry gauging. As a suggestion, besides the improvements on the mentioned problems, the implantation of management and strategy of inventories, of programs and quality control, development of the producing agents, planning and methods of solution of problems. The decline in the quality of the raw material, corn, can result in chain effect, damaging the final product, thus damaging the financial results of the organization.

KEYWORDS: Corn, Storage, Quality, Production, Control. 


\section{INTRODUÇÃO}

Quando da análise das cadeias produtivas, é preciso visualizar os pormenores de cada fase, de forma que a jusante sempre se tenha o melhor produto, contribuindo para profissionalização dos agentes e suas atividades, logo, rendimentos maiores. Considerando a lógica do agronegócio, após porteira, especificamente a indústria, é que o tema deste artigo se debruça, propondo-se a avaliar a qualidade do milho e suas condições durante o processo de armazenagem em silo a granel, identificando fatores que favoreçam ou prejudiquem o grão no momento que antecede a produção de alimentos para consumo humano, em uma indústria localizada no município de Apucarana, no Estado do Paraná.

O uso de armazéns, de certa forma, possibilita a redução de custos com transportes, e por outro lado, garante o fornecimento em "tempo real" de matéria prima para produção, e no caso estudado, para processamento e derivação. Porém, é necessário inspeção e gerenciamento no processo de estocagem e sobre o produto armazenado, para que a qualidade do mesmo seja, ao mínimo, preservada. Assim, a armazenagem se apresenta como uma importante ferramenta para as empresas, garantindo a disposição dos materiais e a conservação dos produtos que estão recolhidos nas estruturas das indústrias. Desta forma, e seguindo a linha de raciocínio de Scussel (2000) referente a qualidades dos grãos, devem-se levar em consideração as condições que o produto será armazenado, período de tempo e processamento, que pode ser tanto para fins de consumo humano quanto animal.

A capacidade de preservação da qualidade, da sanidade e do valor nutritivo dos grãos, não depende só das condições de produção e de colheita, mas também de armazenagem, manutenção e condições adequadas de estocagem do produto (SCUSSEL, 2000). Segundo Brooker Et. al. (1992), as principais características que determinam a qualidade dos grãos são: teor de água baixo e uniforme; percentuais reduzidos de material estranho, de descoloração, de susceptibilidade à quebra, de danos pelo calor (trincas internas), danos causados por insetos e fungos.

Referente aos fatores que podem influenciar no processo de moagem via úmido ou ainda na qualidade final do produto, pode ser classificado em dois tipos: os inerentes ao próprio milho que se relacionam com o pigmento do grão, granulometria e textura, e fatores não inerentes ao milho que são provenientes dos processos tanto de produção quanto colheita e pós colheita (SCUSSEL, 2000). $\mathrm{Na}$ empresa em estudo, o processo de moagem do milho para a produção de canjica e fubá é chamado moagem úmida, pois destina a separar os componentes do grão que são: amido, gérmen, casca e proteína. Esses componentes podem ser utilizados tanto na fabricação de produtos alimentícios (consumo humano), e não alimentícios como, na indústria têxtil, mineração, entre outros.

É essencial que a qualidade dos grãos seja protegida, mantendo-os sadios, limpos e livres de impurezas, pois, mesmo com a alta tecnologia no processo de moagem úmida, o processamento depende de uma matéria prima fornecida com atributos, principalmente, para gerar produtos com valor agregado, que se destaquem em meio ao mercado competitivo de alimentos.

Além da umidade e da temperatura, os danos mecânicos e as impurezas também influenciam nas condições dos produtos armazenados. Os grãos têm a sua qualidade comprometida pelo ataque dos insetos e dos fungos, que, em uma massa com excesso de umidade e calor, encontram ambiente ideal para a proliferação e a consequente deterioração quantitativa e qualitativa da massa armazenada. Grãos secos, sem excesso de água, impedem o desenvolvimento dos fungos e os seus danos altamente nocivos (WEBER, 2001).

Muitas vezes por déficit de armazenamento ou mesmo por falta de informações, os grãos acabam sendo armazenados de maneira incorreta, em condições inadequadas. Desta forma, o estudo 
visa igualmente, propor sugestões de melhorias para melhorar as condições de armazenagem, consequentemente favorecendo a guarnição das características necessárias para o milho estocado, para posteriori processamento. Na prática, entende-se que matéria prima preservada e bem dimensionada, diminui custos, aumentando ganhos e favorece a derivação de produtos com valor agregado, competitivos e que atendam referências estabelecidas, principalmente em relação a segurança alimentar.

Especificamente no agronegócio e cadeias produtivas de grãos, o propósito da armazenagem é guardar matérias primas por determinado período de tempo, mantendo suas características e composição físico química, como carboidratos, proteínas, fibras e vitaminas, o mais próximo do estado natural, minimizando ou evitando perda do poder germinativo, vigor das sementes e qualidade, até que seja requisitado para utilização (PUZZI, 2000; ALENCAR et. al., 2002). Para tanto, o armazenamento deve ser executado com cuidados extras e externos, evitando umidade, temperaturas desconexas, pragas, fungos e outras intempéries, que possam danificar os grãos, logo o produto final. Por isso se faz necessário manejo e conservação dos equipamentos de armazenagem, além dos grãos e sementes serem monitorados constantemente (ALENCAR Et.al, 2002).

Um dos principais itens a serem observados e tratados durante a armazenagem é a umidade. Portanto, manter temperatura e umidade sobre inspeção garante, por dizer, a qualidade do grão, assegurando o potencial fisiológico das sementes, e as características mínimas necessárias para processamento e derivação (BORDIGNON, 2006). Até porque deficiências em armazenagem geram perdas qualitativas e quantitativas, como mudança de aparência, degradação nutricional, perda de capacidade de germinação, além da presença de insetos e contaminação (WEINBERG Et. al., 2008). Bragantini (2005) sugere umidades entre 11 e 13\%, mantendo o processo respiratório dos grãos baixo, prologando a habilitação do produto.

Para Silva (2009) grãos armazenados com valores acima da umidade crítica sofrem degradação de proteínas, carboidratos e fosfolipídios, produzindo compostos lipossolúveis que contaminam o óleo com impurezas que não estão usualmente presentes, as quais afetam a cor, o odor e o sabor. Além disso, o processo de deterioração é invariavelmente acompanhado da hidrólise de triacilgliceróis. Esse fato é importante, pois, com o armazenamento adequado dos produtos agrícolas são evitadas perdas e preservado seu status. Concordando com Elias (2008), em qualquer circunstância, o armazenamento deve ser compatível com as características e com a quantidade de grãos. Também deve ser levada em conta a estrutura onde são armazenados os grãos, para que possa haver controle e manejo operacional adequados durante o período de armazenamento. As informações a respeito de armazenamento de grãos são limitadas no Brasil, por isso são necessários estudos que gerem conhecimentos fundamentais para que se possa manter a qualidade dos grãos em toda a cadeia produtiva.

Paes (2006) e Elias (2002) concordam entre si e complementam, dizendo que os grãos e sementes devem ser secos e armazenados em ambiente apropriado para a manutenção da sua qualidade, que depende da espécie e variedade, condições ambientais na lavoura, época e método de colheita, processo de secagem e práticas de armazenamento. São de interesse da engenharia as características intrínsecas de grãos e sementes, as condições da colheita, limpeza, processo de secagem e práticas de armazenamento.

No caso do grão protagonista deste estudo, o milho, pode ser armazenado a granel, em silos ou armazéns herméticos, ou em sacarias dentro de armazéns. O sistema a granel é a forma mais comum de se armazenar o milho, em função dos avanços tecnológicos disponíveis aos produtores. Silos ou armazéns, de edificações de concreto ou de estrutura metálica, são os locais onde produtos agrícolas são depositados após a colheita (WEBER, 2001). 
O uso do armazenamento graneleiro é mais utilizado em empresas de médio a grande porte, que necessitam armazenar grandes quantidades de produtos. De acordo com Santos e Mantovani (2004), embora simples e com baixo custo, os silos para carga a granel precisam de adoção de boas práticas de armazenagem, como, aeração periódica, com acompanhamento de umidade, temperatura, além, de ações preventivas e tratamentos, como o expurgo ou fumigação com uso da fosfina, tratamento curativo, e objetiva controlar insetos-pragas das unidades armazenadoras, após detecção da infestação, evitando perdas em peso e qualidade (SANTOS e MANTOVANI, 2004).

Mesmo com essas precauções, a secagem se faz necessária, tendo por objetivos principais, a conservação e a preservação, por longos períodos, das propriedades nutricionais e sensoriais desenvolvidas durante a fase de campo (BIAGI Et. al., 2002).

Porém, pode tornar-se danosa à qualidade do grão. Tudo depende do manejo do produto, temperatura, umidade e fluxo do ar, taxa de secagem, período de exposição ao ar quente (BIAGI et. al., 2002). Por outro lado, pode ser executada, segundo Fleurat-Lessard (2010), em camadas, de forma a se realizar a secagem numa massa de grãos, interrompendo o enchimento do silo, até que esta camada esteja seca. Em seguida, é descarregada nova camada de grãos e realizada nova secagem. Isto se repetirá até que se atinja o limite de armazenagem do silo.

\section{MATERIAIS E MÉTODOS}

O trabalho em questão se formatou em uma indústria de alimentos. Além de processamento e derivação de grãos, como soja, milho, girassol e canola, a empresa fabrica alimentos, e fornece matéria prima, como óleo, para outros segmentos, como mineração, cervejaria e para fabricação de ração animal. Precisamente na planta industrial instalada no Município de Apucarana, no Norte do Estado do Paraná, objeto deste estudo, a empresa trabalha basicamente com milho transgênico, onde deriva fubá, canjica e óleo bruto.

A Figura 1 apresenta através de um framework o projeto metodológico do estudo. Salientando que basicamente se caracteriza como estudo de caso, com pesquisa exploratória.

Figura 1. Framework do Projeto Metodológico

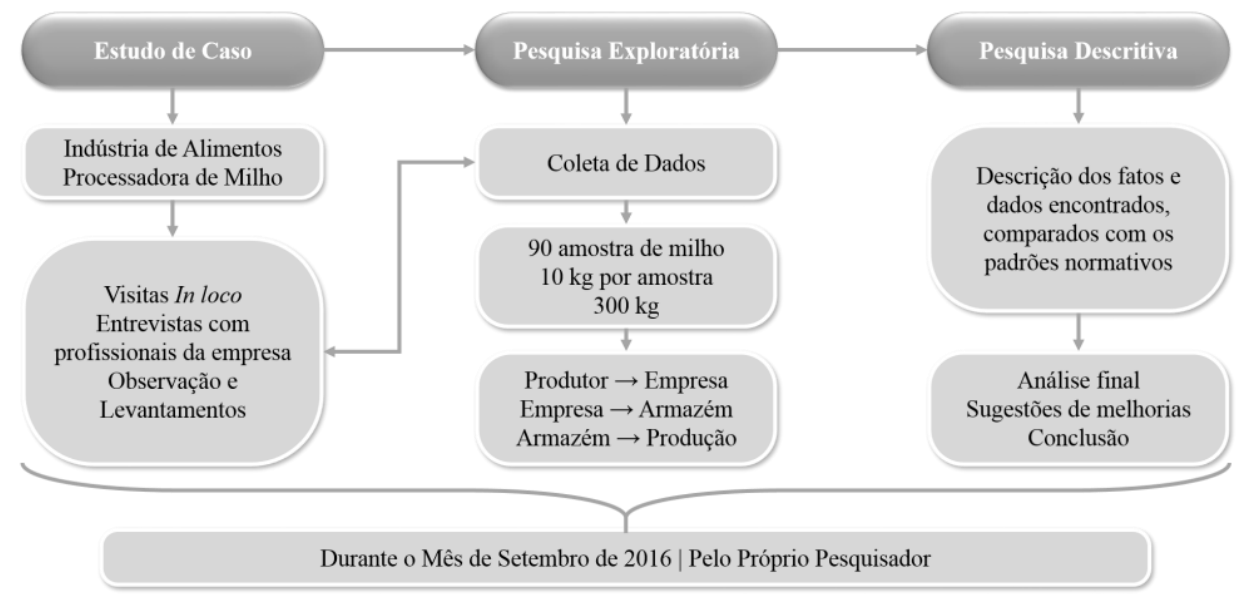

Fonte: Autores, 2016. resultados.

Demais detalhes da construção do estudo, vão sendo descritos durante a apresentação dos 


\section{RESULTADOS E DISCUSSÃO}

Para a coleta de amostras de grãos dos caminhões, utilizou-se caladores pneumáticos, manuais para retirada do silo, e uso de um recipiente (balde) para retirada da produção, com o auxílio de funcionários. Foram retirados aproximadamente $10 \mathrm{~kg}$ de milho por amostras onde as mesmas foram encaminhadas para a sala de recebimento e classificação de grãos para que pudessem realizar as análises solicitadas.

A Tabela 1 expõe a quantidade de matéria prima recebida na empresa através dos fornecedores, e a amostra de análise.

Tabela 1. Entrada de matéria prima na empresa

\begin{tabular}{c|c|c|c}
\hline Caminhões & $\begin{array}{c}\text { Quantidade de matéria } \\
\text { prima recebida (Mil kg) }\end{array}$ & $\begin{array}{c}\text { Média por caminhão (Mil } \\
\text { Kg) }\end{array}$ & Amostra para análise $(\mathrm{Kg})$ \\
\hline 30 & $10.180 .400,04$ & $33.934,68$ & 300 \\
\hline
\end{tabular}

Fonte: Dados da pesquisa 2016.

Para realizar as análises, todas as amostras retiradas dos caminhões, produção e armazém, passaram pelo seguinte procedimento: as amostras foram homogeneizadas para que 250 gramas fossem retiradas, a empresa em estudo não dispõe de quarteador (equipamento para separação em partes iguais das amostragens), sendo assim o procedimento é realizado manualmente, em seguida foram submetidas a análises seguindo a Instrução Normativa $n^{\circ} 60$ (22/ 12/ 2011), onde os padrões são definidos e apresentados pelo Ministério da Agricultura e Pecuária (BRASIL, 2011).

Para um melhor conhecimento sobre os indicadores analisados, a Figura 2 apresenta as características de cada indicador verificado durante o estudo.
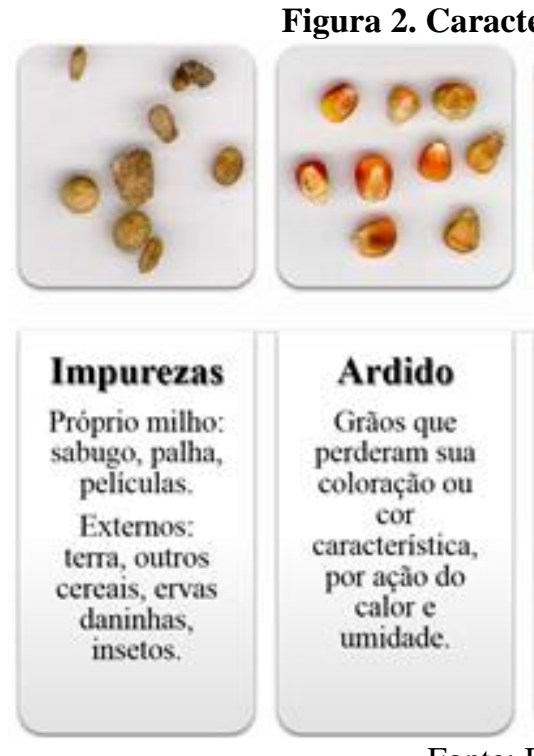
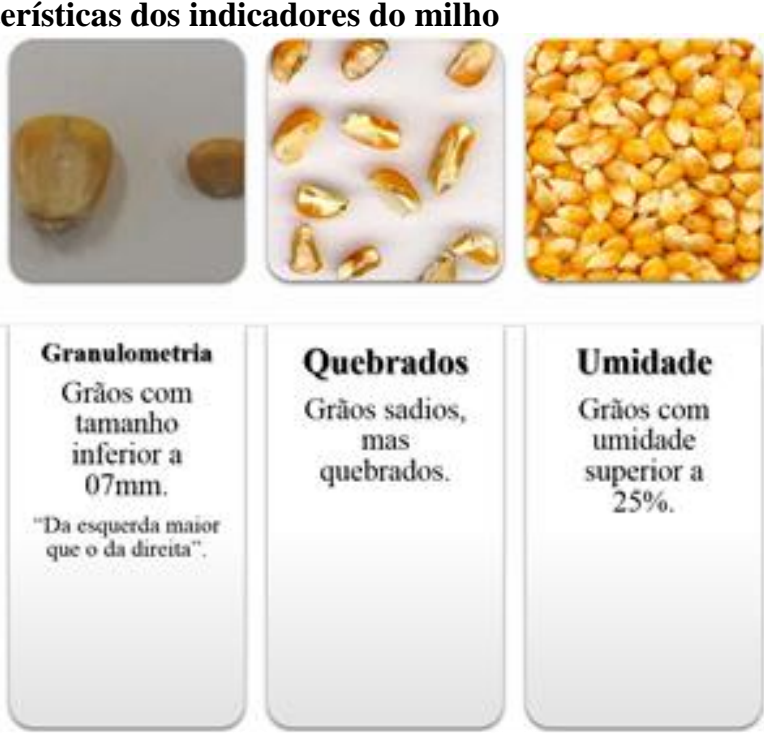

Fonte: Dados da Pesquisa, 2016.

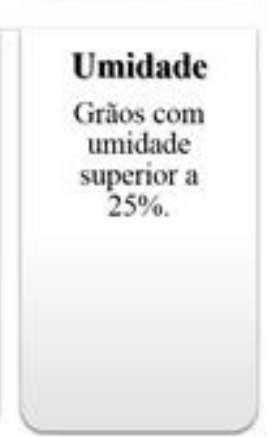

Um dos instrumentos mais utilizados para o controle da qualidade no processo que antecede a armazenagem é a classificação dos grãos, que é a determinação das características de um produto, com base em padrões qualitativos previamente elaborados, conforme resolução $\mathrm{n}^{\circ} 60$, de 22 de dezembro de 2011 (ELIAS, 2002). Tais padrões são definidos e apresentados na Tabela 2 pelo ministério da agricultura e pecuária (BRASIL, 2011). 
Tabela 2 - Especificação Técnica do milho

\begin{tabular}{l|l|l}
\hline \multicolumn{1}{c|}{ Análises } & \multicolumn{1}{|c|}{ Recebimento - Milho úmido } & \multicolumn{1}{|c}{ Milho para o processo } \\
\hline Umidade & 14,1 à $25 \%$ & Máx 14,0\% \\
Impurezas & 0,5 à $1,5 \%$ & Máx $1,0 \%$ \\
Grãos ardidos & Máx $2,0 \%$ & Máx $1,0 \%$ \\
Grãos quebrados & Máx $4,0 \%$ & Máx 3,0\% \\
Grãos carunchados & Máx 2,0\% & Máx $1,5 \%$ \\
Granulometria peneira $7 \mathrm{~mm}$ & Máx 10,0 $\%$ & Máx 10,0\% \\
Insetos Vivos & Ausente & Ausente \\
Sementes tóxicas & Ausente & Ausente \\
Odor de fumaça & Ausente & Ausente \\
Soja & Ausente & Ausente \\
Terra/pedra & Ausente & Ausente \\
\hline
\end{tabular}

Fonte: BRASIL, (2011); Adaptado pelos Autores, 2016.

Os indicadores normalmente são observados durante a safra de inverno, onde o cereal recebido é chamado milho úmido, devido ao processo da colheita e logo após o direcionamento para a central de recebimento, onde o mesmo será destinado para a cadeia de processo.

Para realizar a classificação é necessário seguir alguns critérios exigidos em norma, sendo necessário retirar todos os quebrados, ardidos, miúdos (grãos que possuem a granulometria inferior a $07 \mathrm{~mm}$ ), grãos carunchados e impurezas. Sendo assim as 250 gramas de milho foram peneiradas, com a utilização de peneiras com diâmetro de 7 e $5 \mathrm{~mm}$. Os grãos que apresentaram os indicadores de qualidade mencionados foram separados, pesados e avaliados conforme a especificação. E para a verificação da umidade presente nos grãos é utilizado um motomco (equipamento digital que determina o teor de umidade). Após estes procedimentos aproximadamente $1 \mathrm{~kg}$ de produto é acondicionado em sacos plásticos específicos para este procedimento, onde são guardados por um período de 05 dias.

Caso a amostra coletada apresente odor de fumaça, sementes tóxicas, insetos vivos, pedra, terra e soja, a carga é devolvida para o produtor, pois estes fatores têm forte influência na qualidade da matéria prima durante sua armazenagem prejudicando o produto final. A partir destas informações, foi possível realizar as análises a fim de observar quais fatores apresentam maiores índices, para que seja possível realizar uma análise de quais tem maior influência no processo de armazenagem, a ponto de estarem prejudicando os produtos finais. Após as informações coletadas, as mesmas são apresentadas no Gráfico 1, para que se possa ter um melhor entendimento sobre os indicadores levantados.

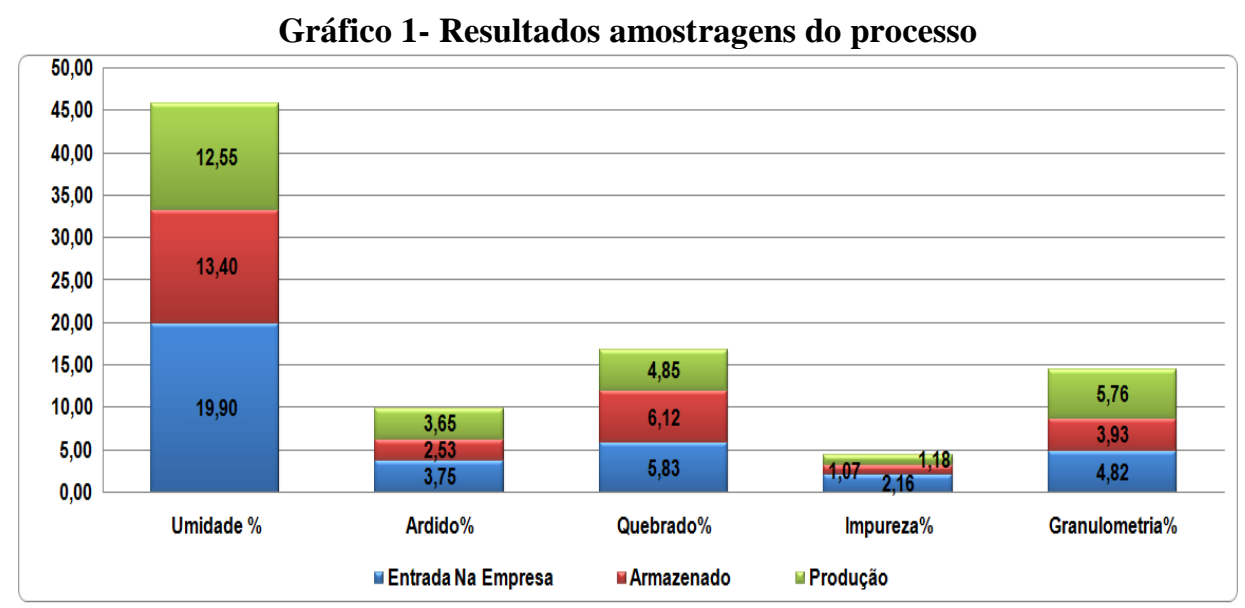

Fonte: Dados da pesquisa 2016. 
É possível observar que a umidade apresentada está dentro do limite conforme especificação, que pode ser até $25 \%$ para o milho úmido no recebimento, e de $14 \%$ para a produção.

Se a umidade estiver acima de $25 \%$ no recebimento, estará prejudicando de maneira direta todo o processo de secagem deste milho, pois o mesmo precisará passar mais vezes pelo processo, aumentando o custo de produção final. Outro fator é o tempo que ele permanece nas moegas, pelo fato do mesmo apresentar um alto índice de umidade a tendência é que o mesmo fermente criando mofos na massa dos grãos.

Caso o milho seja encaminhado para a armazenagem com umidade superior a $14 \%$, o risco das massas de grãos sofrerem alterações químicas é alto, ocasionando mofos e aumento do índice de ardidos, o que é prejudicial para o produto final.

No que se refere aos ardidos tanto para o recebido quanto para a matéria prima que esta sendo destinada a produção, os indicadores se mostraram acima do limite permitido que é de $2 \%$ para a entrada na empresa e de $1 \%$ para a entrada na produção. Estes resultados podem influenciar a qualidade do produto final. De acordo com a Embrapa (2005), são considerados grãos ardidos todos aqueles que possuem pelo menos um quarto de sua superfície com descoloração, cuja matriz pode variar de marrom claro a roxo ou ainda de vermelho claro para vermelho intenso. Devido a estes fatores a qualidade do produto final é prejudicada, o mais comum é o surgimento de pontos escuros no produto após o processamento.

O quebrado, da mesma forma que o ardido, se mostra acima da especificação, onde para este indicador o máximo permitido para a entrada na empresa é de $4 \%$ e para a entrada na produção de $3 \%$. Este fator prejudica o processo de produção de canjica devido à perda do endosperma do milho que é o princípio ativo do produto mencionado. As impurezas como os ardidos alteram a qualidade final do produto, apresentando pontos pretos nos produtos processados. Vale ressaltar que essas impurezas são inerentes ao próprio milho, em que no gráfico, é possível observar que os resultados se mostraram acima da especificação que é de 1,5\% para a entrada na empresa e de $1 \%$ para a entrada na produção.

No indicador de granulometria os resultados são positivos, conforme representada no gráfico, se mantendo dentro das especificações técnicas de insumos que é de $10 \%$ para a entrada na empresa e produção. No Gráfico 2 são apresentadas as diferenças percentuais entre os indicadores analisados, para que seja possível observar a diferença de cada etapa do produto dentro da empresa até a produção do derivado final.

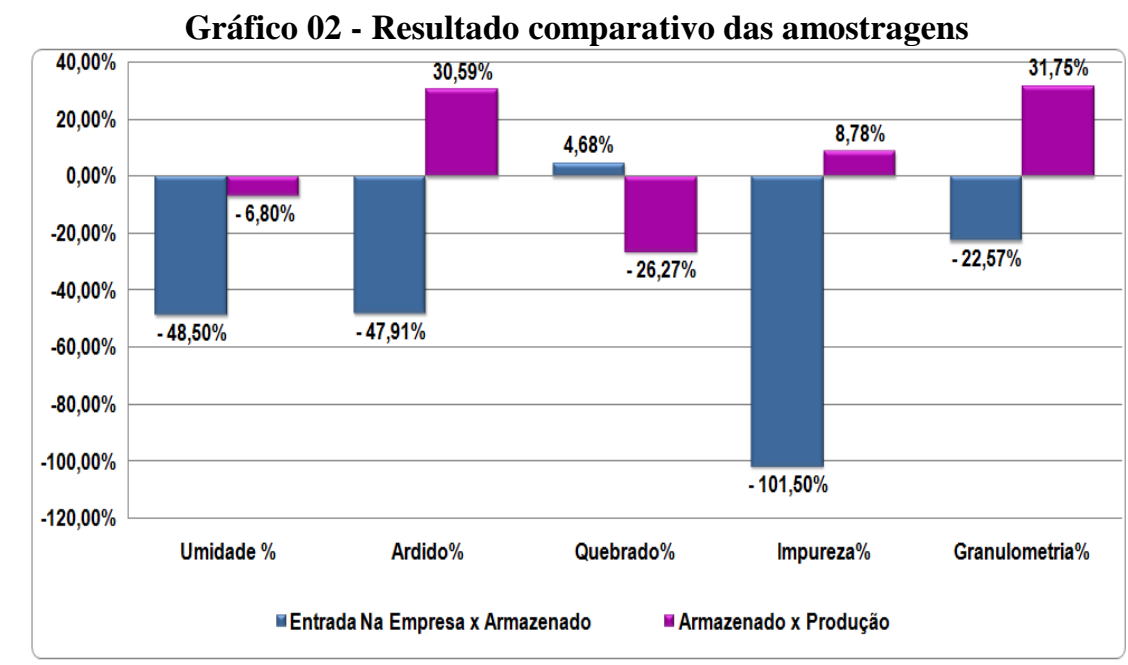

Fonte: Dados da pesquisa 2016. 
Nota-se que o milho sofreu redução da umidade, do momento em que chegou na empresa para o momento que foi destinado para a armazenagem. Este fator resultou em uma diferença percentual positiva, pois no que se refere à umidade do milho, quanto menor de $14 \%$, mais favorável para a conservação do grão que está armazenado dentro dos silos, pois dificulta que ocorram alterações em sua qualidade.

Em relação ao "armazenado para a produção", a umidade também apresentou uma redução positiva. Este fator é possível devido ao tempo que o milho fica guardado e é exposto a aeração, onde o mesmo tende a perder umidade. Como a empresa trabalha com a produção de canjica e fubá, produtos que necessitam de milho mais seco, a umidade que foi analisada esta dentro dos padrões esperados para um bom processo produtivo.

Nos ardidos, houve redução do índice entre o milho que foi recebido e o armazenado. Tal redução se deve pelo processo que antecede a armazenagem do produto, pois a máquina de pré limpeza retira os grãos que apresentam este indicador encaminhando para a armazenagem um cereal mais limpo.

Durante a armazenagem, o grão pode ter aumento ou redução de ardidos, vai depender de como este cereal está sendo cuidado, e da manutenção do silo. E as análises realizadas demonstraram que o milho disponibilizado para a produção teve aumento de ardidos, sendo que este fator para a produção de canjica e de fubá é negativa, e demonstra que os cuidados durante seu armazenamento estão sendo ineficientes.

Para os quebrados é possível observar que ouve um aumento quando o grão entrou para o armazenamento. Este fator pode acontecer decorrente do transporte do cereal pelas etapas que antecede a armazenagem ou a maneira que o grão foi colocado dentro do silo. Uma possível causa está no silo vertical e sua altura, principalmente quando está vazio, Pois o grão cai para o fundo do silo, ocasionando sua quebra.

Quando o milho é encaminhado para a produção, o mesmo passa pela pós limpeza e através de canais de aspiração os fragmentos do milho são aspirados, sendo assim os quebrados por serem leves são retirados. Este fator resulta no que o gráfico demonstra, a redução de quebrados encaminhados para a produção. Para a retirada da impureza o processo de pré limpeza é essencial. O resultado mostra que o cereal recebido no momento que deu entrada no silo, está mais limpo e livre de impurezas.

Quando o mesmo foi encaminhado para o processo produtivo, os índices são maiores, isso é possível da mesma maneira que os quebrados, devido à altura dos silos. Com a quebra dos grãos o resultado são fragmentos, estes considerados como impureza no processo. Na granulometria, o que está entrando na empresa para o que está sendo encaminhado para a produção, teve redução, devido à limpeza dos grãos, que por serem mais leves são retirados pelos canais de aspiração.

Para a produção o resultado de granulometria teve aumento, quando se refere a este indicador para a produção é um sinal positivo, pois significa que os grãos passaram pela secagem, reduzindo seu teor de umidade e resultando na diminuição do tamanho do grão, ficando este abaixo de $7 \mathrm{~mm}$. Para que seja possível observar os números com mais clareza, a Tabela 2 demonstra, de maneira mais objetiva, os resultados dos indicadores.

Tabela 2. Variações das amostragens no processo

\begin{tabular}{l|c|c|c|c|c}
\hline \multicolumn{1}{c|}{ Tipo } & Umidade \% & Ardido\% & Quebrado\% & Impureza\% & $\begin{array}{c}\text { Granulometria } \\
\%\end{array}$ \\
\hline Entrada na empresa & 19,90 & 3,75 & 5,83 & 2,16 & 4,82 \\
Armazenado & 13,40 & 3,65 & 6,12 & 1,07 & 3,93 \\
\hline
\end{tabular}




\begin{tabular}{l|c|c|c|c|c}
\hline Produção & 12,55 & 2,53 & 4,85 & 1,18 & 5,76 \\
Entrada $X$ armazenado & $-48,50$ & $-47,91$ & 4,68 & $-101,50$ & $-22,57$ \\
Armazenado $X$ produção & $-6,80$ & 30,59 & $-26,27$ & 8,78 & 31,75 \\
\hline
\end{tabular}

Fonte: Dados da pesquisa 2016.

Ressalta-se que, para conseguir ter uma boa qualidade dos produtos, a pós colheita é de suma importância, pois nesta fase é definida a conservação e a qualidade do produto que será armazenado. A empresa em estudo trabalha exclusivamente com a armazenagem de um único produto, o milho transgênico, onde o mesmo é recebido de vários produtores da região Norte do Estado do Paraná, durante todo o ano em diferentes safras.

O processo de armazenagem consiste em etapas que são cuidadosamente executadas para que possa garantir que a qualidade do cereal armazenado seja preservada, pois o intuído da armazenagem não é melhorar a qualidade e sim preservar a mesma até que seja destinada para a produção. Para entender melhor o processo que o grão percorre dentro da empresa, foi elaborado um fluxograma (Figura 3), que consiste em demonstrar o caminho percorrido do milho em sua transição do recebimento até armazenagem e a posteriori produção.

Figura 3- Fluxograma armazéns gerais

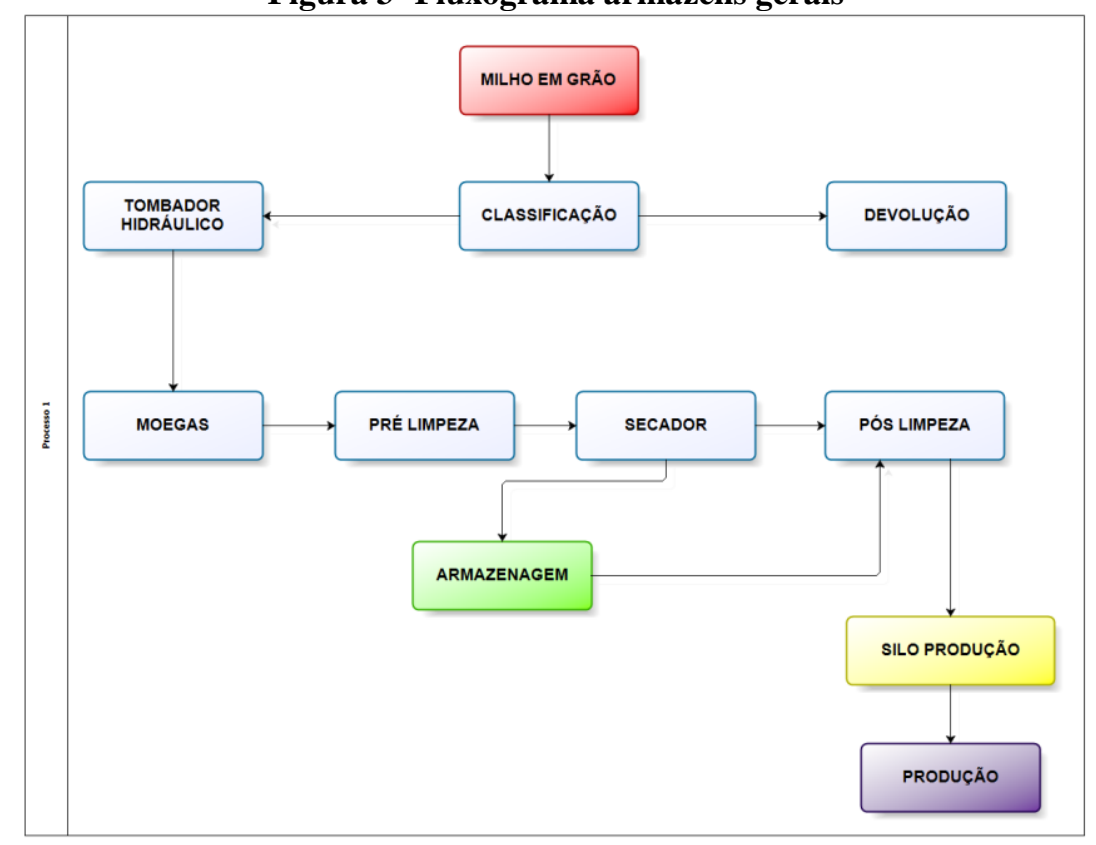

Fonte: Dados da Pesquisa, 2016.

Após serem descarregados, os grãos são transportados através de elevadores de canecas e por redlers de correntes até as moegas, onde o milho ainda úmido permanece por no máximo dois dias até ser direcionado para a pré limpeza.

De acordo com Silva (2009), os elevadores de canecas ou caçambas são meios de transportes ideais para material granular. De maneira geral trabalham na posição vertical, neste sistema o produto é elevado a uma altura que possibilita sua distribuição por gravidade.

Com a utilização de uma fita transportadora de grãos, o milho é encaminhado para a pré limpeza, importante fase para o processo de armazenagem, pois além de aumentar a qualidade dos grãos armazenados, diminuem o consumo de energia nos secadores. 
$\mathrm{Na}$ empresa estudada, a secagem é de forma direta em altas temperaturas, ou seja, possui fornalha que aquece o ar e esse passa pela massa de grãos arrastando a umidade para fora do secador.

Para queima nas fornalhas do secador, é utilizado combustível renovável conhecido como briquete. De acordo com Dantas (2012), este combustível apresenta algumas propriedades importantes como: calor homogêneo, maior temperatura da chama, pouca produção de fumaça, cinza e fuligem, fator relevante para o processo de secagem, pois o ar quente produzido pelas fornalhas passa pela massa de grãos, por este motivo é muito importante que o ar esteja limpo e sem odor de fumaça, para que a matéria prima não sofra alterações.

O cereal já seco deve ser encaminhado para o silo com umidade inferior a $14 \%$, ainda quente ele é armazenado, inicia-se o processo de resfriamento desses grãos com a utilização de ventiladores, este procedimento se aplica quando o destino é a armazenagem. Para que seja possível ter um controle da temperatura interna do silo é utilizado equipamentos de termometria, onde sensores são acoplados no interior da massa dos grãos através de cabos de cobre, para que seja possível a verificação do calor emitido pela massa de grãos.

Antes da produção, o milho passa pela pós limpeza, indo para os silos da produção, onde é controlado igualmente por termometria automatizada, e fica armazenado por períodos de no máximo 20 dias, até entrar para derivação.

Os silos a granel são considerados mais seguros para o armazenamento de sementes, pois permite um controle da qualidade, devido à facilidade de associação com os sistemas de aeração e do controle de temperatura através da termometria (EMBRAPA, 2011).

Durante o estudo de caso foi possível observar alguns casos isolados de falhas que podem comprometer a qualidade dos produtos que estão sendo armazenados. A falta de acompanhamento da termometria, ou ainda a falta de se fazer aeração, faz com o que o milho que está dentro dos silos eleve a temperatura, este processo provoca a transpiração dos grãos propiciando a propagação de fungos e pragas dentro da massa dos grãos, alterando a sua qualidade, o resultado são grãos ardidos.

Em períodos onde as temperaturas são mais elevadas, é necessário que os cuidados sejam maiores, pois as altas temperaturas podem aquecer as paredes dos silos, fazendo com que o produto que está sendo armazenado sofra as consequências deste aquecimento, o resultado é a fermentação dos grãos ou até mesmo a propagação de carunchos, pragas muito comuns em processos de armazenagem.

Problema comum em processos de armazenagens de grãos é o chamado fundo do silo, onde o cereal armazenado fica depositado no fundo por mais tempo. O milho é retirado pela lateral, e o que sai da armazenagem vem de cima do silo por gravidade, ficando os grãos que caíram no silo por primeiro, armazenados por períodos mais longos, como consequência, transformando grãos sadios em ardidos.

No caso da empresa, o milho é encaminhado para o processo de produção, pois no momento não existe nenhum sistema instalado para descarte, ocasionando no produto final o aparecimento de pontos escuros decorrentes da coloração dos grãos. Após todos os levantamentos realizados com detalhamento dos indicadores da qualidade do milho, o mesmo passa por fatores adversos que podem comprometer totalmente a sua qualidade antes do processo produtivo.

Desta maneira, um processo de armazenagem executado de maneira eficiente, desde o recebimento até a destinação para a produção, conforme padrões estabelecidos pelo Ministério da Agricultura e Pecuária, são significativos para garantir a qualidade do grão. No quadro 4, tem-se 
uma breve descrição das características, causas e do processo de armazenagem que influenciam o grão.

Quadro 4- Características, causas e possíveis soluções para qualidade na armazenagem.

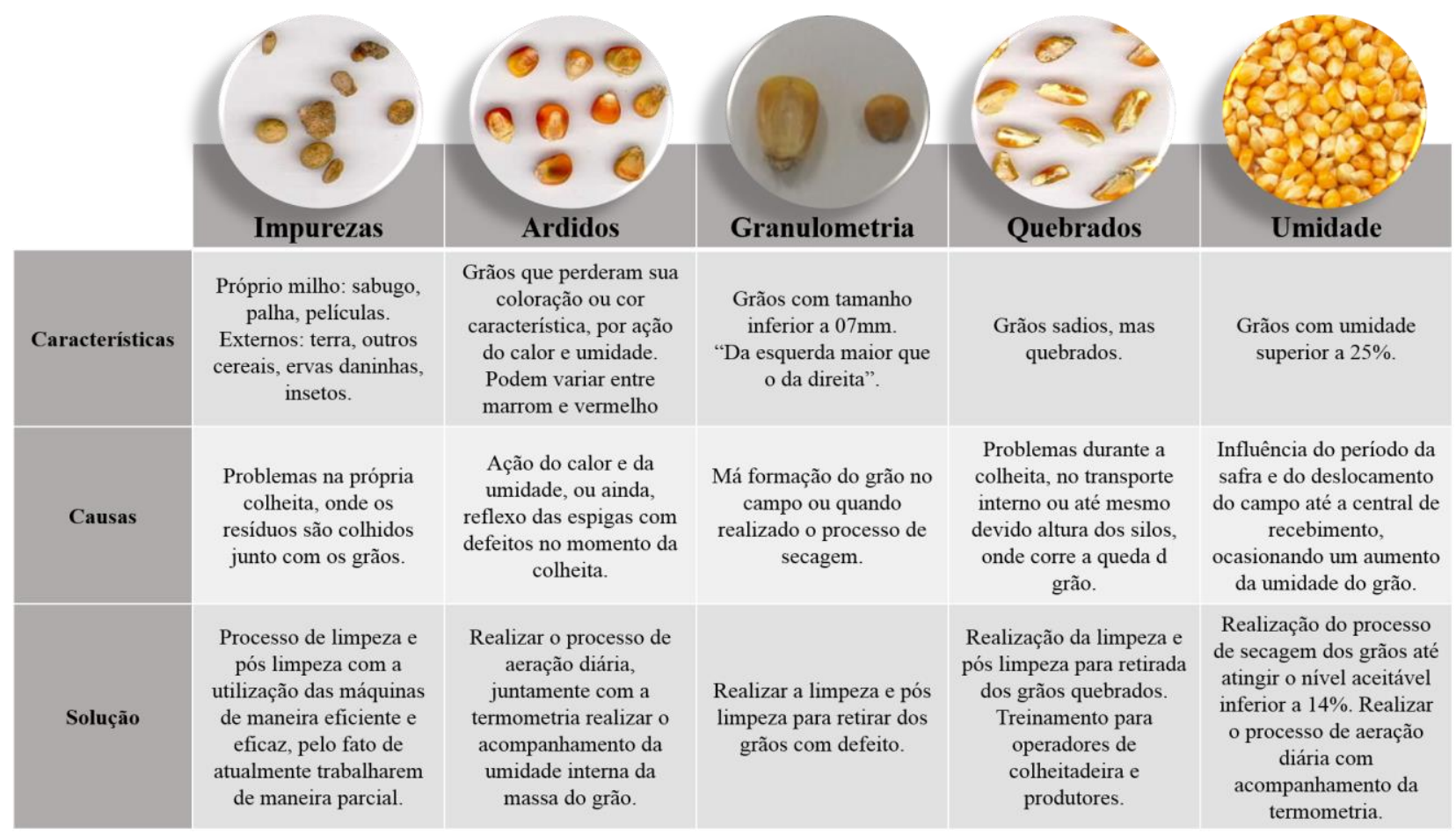

Fonte: Elaborado pelos autores, 2016.

Mediante o exposto, evidencia-se que, para conseguir ter um produto final com qualidade, a armazenagem e o processo que antecede são de extrema importância. Pois a armazenagem pode contribuir de maneira direta com a perda de qualidade dos grãos.

Através deste trabalho, pode ser levantado todos os fatores que influenciaram de alguma maneira a qualidade do milho para a produção de alimentos durante a armazenagem. Quando o milho é recebido na empresa, alguns indicadores são levados em consideração para contribuir no processo de armazenagem. Assim, pode ser observado durante as análises das amostras coletadas que alguns indicadores se mostraram fora dos padrões que são estabelecidos pelo Ministério da Agricultura e Pecuária, conforme ficou demonstrado no gráfico 1.

Quando da entrada na linha de produção, foi possível identificar fatores adversos que comprometeram sua qualidade. Conforme o gráfico 1, os dados analisados mostraram que alguns indicadores estão fora das especificações, presumindo que existem falhas antes e durante o processo de armazenagem para a produção. Após realizar o levantamento de dados, a fim de identificar os principais aspectos internos da empresa em relação a armazenagem, propõe-se soluções para a manutenção da qualidade do milho durante seu processo de armazenagem.

\subsection{Proposição de Melhorias}

Mediante ao identificado e analisado em relação ao processo de armazenagem, e partindo dos dados colhidos, apresenta-se a algumas sugestões de melhorias. No Quadro 5 apresentam-se propostas, com intuito de tornar mais eficiente e eficaz o processo produtivo da empresa estudada, diminuindo perdas de produto e tornando a empresa mais lucrativa. 


\begin{tabular}{|l|l|}
\hline \multicolumn{2}{l}{ Quadro 5- Sugestões de melhorias para a armazenagem de grãos } \\
\hline Item & Proposta \\
\hline Ardidos/ impurezas & $\begin{array}{l}\text { Programa de conscientização e treinamento dos colaboradores, para que sigam as } \\
\text { especificações da RDC n } 60 \text { de } 22 \text { de dezembro de } 2011 \text { do Ministério da Agricultura e } \\
\text { Pecuária, para que não ultrapassem a margem que a legislação indica. }\end{array}$ \\
\hline Ardidos & Aeração diária com acompanhamento da termometria. \\
\hline Impurezas & Trocar os filtros de manga manuais por filtros com limpeza automática. \\
\hline Impurezas & Aumentar a eficiência das máquinas de pré e pós limpeza. Aplicar a manutenção preventiva. \\
\hline Impurezas/ardidos & $\begin{array}{l}\text { Treinamento dos colaboradores sobre a importância de realizar a troca regular dos filtros de } \\
\text { manga, realizar a limpeza das peneiras e regulagem do canal de aspiração. }\end{array}$ \\
\hline Fundo do Silo & $\begin{array}{l}\text { Adaptação dos equipamentos (elevador e tubulações), para retorno da matéria prima para o } \\
\text { processo de limpeza. }\end{array}$ \\
\hline Pragas & Planejamento para realização de expurgo preventivo com fosfina e aeração diária. \\
\hline
\end{tabular}
Fonte: Elaborado pelos Autores, 2016.

Estas ações têm por objetivo melhorar o processo de armazenagem, para que o produto que está sendo guardado se mantenha com o máximo de qualidade até ser requisitado para a produção. São medidas simples e fáceis de serem aplicadas e com baixo custo, com retorno satisfatório, pois o resultado está ligado diretamente com os produtos fabricados na empresa em estudo.

Em complemento, indica-se a aplicação e uso de ferramentas de gestão, especificas para gerenciamento de estoque e linhas de produção, conforme demonstra o Quadro 6. Porém, antes, sugerem-se medidas da empresa em relação ao produtor, seu principal fornecedor. Criar programas de melhoramento genético da matéria prima milho, e projeto de desenvolvimento de agentes, os produtores. Desde a produção (escolha de sementes, manejo, assistência, etc.), até a colheita (regulagem de máquinas, processo correto de colheita, manutenção preventiva, etc.). A ideia é receber produtos com maior grau de aptidão e particularidades inerentes a necessidade da empresa, nesse caso para produção de canjica, fubá e óleo, diminuindo nas fases subsequentes riscos de baixa na qualidade, e facilitando a gestão do processo, procurando eliminar desperdícios, quebras e prejuízos.

Quadro 6- Ferramentas de Gestão e Produção

\begin{tabular}{|l|l|}
\hline \multicolumn{1}{|c|}{ Ferramentas } & \multicolumn{1}{c|}{ Descrição } \\
\hline Kanban & $\begin{array}{l}\text { Indica o andamento dos fluxos de produção. } \\
\text { A utilização de um sistema Kanban permite um controle detalhado de produção } \\
\text { com informações sobre quando, quanto e que produzir. }\end{array}$ \\
\hline Just in time - JIT & $\begin{array}{l}\text { Armazena-se o mínimo de matéria prima em estoque, apenas em quantidade que permita } \\
\text { manter o processo produtivo no momento. }\end{array}$ \\
\hline Gestão de Estoques & $\begin{array}{l}\text { Gestão dos recursos materiais que podem ajudar a organização a gerar receita no futuro. } \\
\text { FIFO - "First in, first out”: primeiro [produto] a entrar no armazém deve ser também o } \\
\text { primeiro a sair, com o objetivo de evitar a perda, quebras, etc. } \\
\text { LIFO - Last In, First Out”: último a entrar, primeiro a sair. } \\
\text { FEFO - "First Expired, First Out": primeiro que vence é o primeiro a sair". }\end{array}$ \\
\hline Gestão da qualidade & $\begin{array}{l}\text { "Grau no qual um conjunto de características inerentes satisfaz a requisitos". } \\
\text { Foco na qualidade do processo de produção, dos produtos e serviços de determinada } \\
\text { empresa. Inicia-se na escolha da matéria prima, com características especificas para o } \\
\text { produto fim. }\end{array}$ \\
\hline 5S & $\begin{array}{l}\text { Reduzir o desperdício de recursos e espaço de forma a aumentar a eficiência operacional. } \\
\text { Permite desenvolver uma melhoria contínua na destinação dos materiais. }\end{array}$ \\
\hline
\end{tabular}




\begin{tabular}{|l|l|}
\hline $\begin{array}{l}\text { PCP - Planejamento e } \\
\text { Controle de Produção }\end{array}$ & $\begin{array}{l}\text { Processo utilizado no gerenciamento das atividades de produção, incluindo uso de matéria } \\
\text { prima, destino e processamento. } \\
\text { Passando por programação e controle, além de quantidade, layout, fluxo de insumos e o } \\
\text { passo a passo da transformação. }\end{array}$ \\
\hline $\begin{array}{l}\text { Manutenção } \\
\text { Preventiva }\end{array}$ & $\begin{array}{l}\text { Toda a ação sistemática de controle e monitoramento, com o objetivo de reduzir ou impedir } \\
\text { falhas no desempenho de equipamentos. Visa aumentar a confiabilidade e leva o } \\
\text { equipamento a operar sempre próximo das condições exclusivas a que se destina. }\end{array}$ \\
\hline
\end{tabular}

Fonte: SHINGO, 1996 ${ }^{\mathrm{a}}$, ; TUBINO, 1999; MARTINS \& LAUGENI, 2005; FERRO, 2011. Adaptado pelos Autores, 2016.

Essas sugestões visam, além de melhorar o processo de armazenagem, ou ao menos contribuir, complementando-o, mostrar que é possível inserir ferramentas de gestão no agronegócio, em todas as suas etapas e tarefas intrínsecas de cada cadeia produtiva.

Cita-se ainda: o MASP - Método de Análise e Solução de Problemas; O PDCA - Planejar, Fazer, Verificar e Agir; Gestão a Vista - Gestão à base de um sistema que possibilite que os principais itens de controle estejam em fácil acesso a toda a equipe, seja através de gráficos, dados, informações gerenciais que permitam uma rápida e fácil visualização e interpretação dos mesmos; Entre outros. É importante destacar, que para cada ramo, empresa e situação, suas aplicações devem ser orientadas, por vezes, adaptadas a cada necessidade e atividade.

\section{CONCLUSÃO}

O propósito de identificar as condições de armazenagem, e fatores que influenciam na qualidade do milho para a produção de alimentos foi concluído com êxito, onde pode-se observar todo o processo, desde a chegada da matéria prima até seu fornecimento à produção, apontando as condições que o milho é recebido na empresa e quando da entrada na linha de produção.

Um dos indicadores de qualidade verificado, foi à "umidade" presente nos grãos, que não poderiam ultrapassar $25 \%$ para entrada na empresa e $14 \%$ para a entrada na armazenagem, bem como para a produção, conforme descreve a instrução normativa estabelecida pelo Ministério da Agricultura e Pecuária. A média percentual de umidade dos grãos de milho que deram entrada na empresa foi de $19,9 \%$, enquanto para a produção foi de $12,55 \%$, estando dentro dos padrões estabelecidos.

O segundo indicador analisado foi o "ardido", onde o índice de percentual não pode ultrapassar de $2 \%$ para o recebimento na empresa e de $1 \%$ para a produção. O resultado da média analisada foi de $3,75 \%$ para a entrada na empresa, e 3,65\% para a produção, resultados que ultrapassaram os padrões. Estes fatores prejudicam de maneira direta a qualidade da matéria prima que está sendo armazenada, bem como, a qualidade do produto final, ocasionando pontos pretos e alteração de sabor. Medidas simples podem prevenir estas ocorrências como a prática de aeração e o acompanhamento através da termometria.

O terceiro indicador analisado é o dos "quebrados". Para o recebimento deve se apresentar com menos de $4 \%$ e para a entrada na produção 3\%. Nas amostras coletadas, os resultados obtidos foram de 5,83\% para a entrada e 4,85\% para a produção. Resultado acima dos padrões. Estes valores prejudicam o processo de produção de canjica devido à perda do endosperma, característica principal do grão. Uma forma de prevenir é a manutenção preventiva e periódica das máquinas de limpezas e canais de aspirações.

As "impurezas" mesmo que sejam inerentes do próprio milho, também possuem uma taxa de aceitação para entrada na empresa, sendo de $1,5 \%$ e de $1 \%$ para a produção. Durante as análises os resultados foram insatisfatórios apresentando $2,16 \%$ na entrada e $1,18 \%$ na produção. $\mathrm{O}$ fato de 
estarem acima do estabelecido, prejudica de maneira direta os produtos produzidos pela empresa, ocasionando pontos escuros e alteração do sabor. Para que esse problema seja solucionado, é necessário que os colaboradores sigam as especificações técnicas do milho estabelecido pelo Ministério da Agricultura e Pecuária e a realização da manutenção básica das máquinas de limpezas.

O último indicador analisado neste trabalho foi a "granulometria", tanto para a entrada na empresa quanto na entrada da produção, devem ser inferiores a 10\%, onde, durante as análises, os resultados foram de $4,82 \%$ para a entrada e de $5,76 \%$ para a produção, estando dentro dos padrões estabelecidos.

Observa-se que existem variações positivas e negativas sobre os indicadores do milho que chega na empresa e é encaminhado para a armazenagem, e que os resultados são diretamente ligados aos processos de limpeza e secagem dos grãos.

Da mesma maneira que podem ser observadas variações no momento em que o grão é encaminhado da armazenagem para a produção, o que demonstra que o processo de armazenagem e os procedimentos de pós limpeza podem influenciar na qualidade da massa de grãos que é disponibilizado para alimentos de consumo humano.

Após todos os dados coletados e analisados, e o acompanhamento de todo o processo de armazenagem, foi possível observar os aspectos internos da empresa, que possam influenciar, de alguma maneira a qualidade do milho durante a armazenagem, sendo eles: a falta de acampamento da termometria para verificação da umidade interna do silo; falta de aeração diária para controle da umidade da massa de grãos; a presença de impurezas, ardidos, quebrados junto com grãos sadios; ineficiência das máquinas de limpezas; falta de treinamento dos colaboradores em relação às normas estabelecidas pelo Ministério da Agricultura e Pecuária; e o chamado fundo de silo, onde a matéria prima fica depositada ao fundo por longos períodos, ocasionando a transformação de grãos sadios em ardidos e a propagação de carunchos.

É possível propor soluções para a manutenção da qualidade do milho durante sua armazenagem sendo, programa de conscientização e treinamento dos colaboradores referente às especificações da RDC n 60 de 22 de dezembro de 2011; aeração diária com acompanhamento da termometria; troca do sistema de mangas por um sistema automatizado; aumento da eficiência das máquinas de pré e pós limpeza; treinamento para os colaboradores sobre a manutenção das máquinas; implantação de um sistema que retorne o milho que está no fundo do silo para o processo de limpeza, tornando o produto próprio para o consumo; e em relação as pragas, planejamento para realização de expurgo regular com fosfina e aeração diária.

O estudo de case tratou de uma realidade cotidiana e que poderá servir de pesquisas futuras para novos projetos dentro da empresa e outras, podendo ser útil em possíveis mudanças de planejamento e ações de melhorias em relação à armazenagem dos grãos, além de angariar certificações de qualidade.

Por fim, conclui-se que as melhores condições de armazenagem para favorecer a qualidade do milho, é estar dentro dos padrões que são exigidos pelo Ministério da Agricultura e Pecuária, conforme a RDC n60 de 22 de dezembro de 2011. Outros fatores considerados de suma importância são: manutenção dos equipamentos que antecedem a armazenagem, responsáveis pela secagem e limpeza dos grãos, sistema de aeração juntamente com o acompanhamento da termometria, esvaziamento para limpeza interna dos silos e o expurgo com fosfina para o controle de pragas.

Em suma, a qualidade do alimento final derivado, a lucratividade da organização, além do bem estar e segurança alimentar dos consumidores, estão intimamente ligados a gestão de 
armazenagem e movimentação interna da matéria prima central, neste caso, o milho. Além do mais, incorporar-se aos padrões estabelecidos, é de alguma forma, condicionar-se às certificações de qualidade, agregando valor, atraindo exportações, logo, maiores rendimentos para empresa.

\section{REFERENCIAS}

ALENCAR, E.R.; FARONI, L.R.A.; CARDOSO, F.S. Avaliação qualitativa do milho (Zeamays L.) infestado por Sitophiluszeamais durante o armazenamento. In: Simpósio de Iniciação Científica, 12, 2002, Viçosa. Anais. Viçosa: Editora da UFV, 2002. v. 1, p. 5-6.

BIAGI, J.D.; BERTOL, R.; CARNEIRO, M.C. Secagem de grãos para unidades centrais de armazenamento. IN: LORINI, I.; MIIKE, L.H.; SCUSSEL. V.M. (Org.). Armazenagem de Grãos. 1 ed. Campinas - SP: Instituto BioGeneziz (IBG), 2002, v. 1, p. 289-308.

BORDIGNON, Bruno Cesar Silva. Relação das condições de armazenamento com a qualidade fisiológica de sementes e composição do óleo extraído de 118 cultivares de soja. 2009. 90 f. Dissertação (Mestrado em Agronomia) - Universidade Federal de Santa Maria. Santa Maria.

BRAGANTINI, C. Alguns aspectos do armazenamento de sementes e grãos de feijão. Documento Técnico. Santo Antônio de Goiás: Embrapa Arroz e Feijão, 2005, 28 p.

BRASIL, MINISTÉRIO DA AGRICULTURA, PECUÁRIA E ABASTECIMENTO. Instrução Normativa 60/2011. Brasília, 2011.

Brooker et al. (1992), BROOKER, D, B. BAKKER-ARKEMA, F. W.; HALL, C. W. Drying and Storage of Grains and Oil seeds. AVI Book, New York. 1992.

DANTAS, A. P.; SANTOS, R. R. dos; SOUZA, S. C. de. O briquete como combustível alternativo para a produção de energia. III Congresso Brasileiro de Gestão Ambiental Goiânia/GO, 19 a 22/11/2012.

ELIAS, M.C. Manejo tecnológico da secagem e do armazenamento de grãos. Pelotas. Ed. Santa Cruz. 362 p. 2008.

ELIAS, M.C. Tecnologias para armazenamento e conservação de grãos, em médias e pequenas escalas. $3^{\text {a }} \mathrm{Ed}$. Editora Universitária/UFPel. 2002. 218p.

EMPRESA BRASILEIRA DE PESQUISA AGROPECUÁRIA - EMBRAPA. Circular Técnica, 55. Armazenagem de milho a granel na fazenda. EMBRAPA-SP 2011.

EMPRESA BRASILEIRA DE PESQUISA AGROPECUÁRIA - EMBRAPA. Recomendações técnicas para o cultivo do milho. 2.ed. Brasília: EMBRAPA-SPI, 2005. 204p.

FERRO, J. R. Novas fronteiras de aplicação do sistema Lean em serviços. Disponível em: http://www.lean.org.br/artigos/72/novas-fronteiras-de-aplicacao-do-sistema-lean-emservicos.aspx, Set. 2005. Acesso em: 02 Fev. 2011.

FLEURAT-LESSARD, F. Qualitative reasoning and integrated management of the quality of stored grain: a promising new approach. Journal of Stored Products Research, v.38, p.191-218, 2002.

MARTINS, P. \& LAUGENI, F.P. Administração da Produção. 2ed. São Paulo: Saraiva, 2005.

PAES, M. C. D. Aspectos Físicos, Químicos e Tecnológicos do Grão de Milho. Sete Lagoas: Embrapa Milho e Sorgo, 2006. (Embrapa Milho e Sorgo, Circular Técnica 75).

PUZZI, D. Abastecimento e armazenagens de grãos. Campinas: Instituto Campineiro de Ensino Agrícola, 2000. $603 \mathrm{p}$.

SANTOS J. P.; MANTOVANI, E.C. Armazenagem de milho a granel na fazenda. Empresa Brasileira Pesquisa Agropecuária. Circular técnica 55, Sete Lagoas, MG. 06p. Dezembro 2004.

SCUSSEL, V. M. Atualidades em micotoxinas e armazenagem de grãos. Florianópolis: Insular, 2000. 382 p

SHINGO, S. O Sistema Toyota de Produção - Do Ponto de Vista da Engenharia de Produção. Porto Alegre, Bookman, 1996a.

SHINGO, S. Sistemas de Produção com Estoque Zero: O Sistema Shingo para Melhorias Contínuas. Porto Alegre, Bookman, 1996b. 
SILVA, Cynthia Siqueira. Composição química e energia metabolizável de milho segregado pela mesa gravimétrica e sua utilização na formulação de ração para frangos de corte. 2009. 103f. Tese (Doutorado em Ciências) - Escola Superior de Agricultura "Luiz de Queiroz", Universidade de São Paulo. Piracicaba, SP, 2009.

TUBINO, D. F. Sistemas de Produção: a produtividade no chão de fábrica. Porto Alegre, Bookman, 1999.

WEBER, E. Armazenagem Agrícola. Guaíba: Agropecuária, 2001.

WEINBERG, Z.G.; YAN, Y.; CHEN, Y.; FINKELMAN, S.; ASHBELL, G.; NAVARRO, S. The effect of moisture level on high-moisture maize (Zea mays L.) under hermetic storage conditions-in vitro studies. Journal of Stored Products Research, v. 44, n. 2, p. 136-144, 2008 